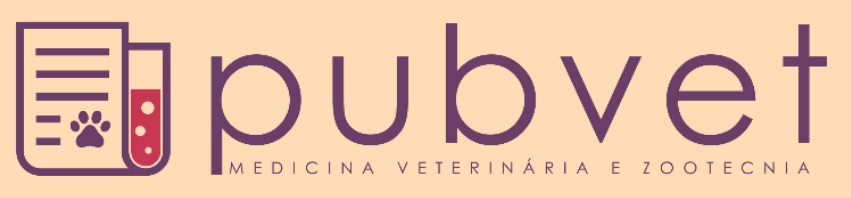

https://doi.org/10.31533/pubvet.v13n10a438.1-12

\title{
Expressão de RNAm de IL1ß, TNF- $\alpha$, TLR2, TLR4 e TLR9 em ovinos imunizados com antígenos de Corynebacterium pseudotuberculosis
}

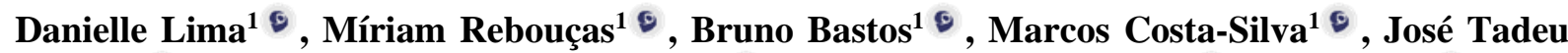

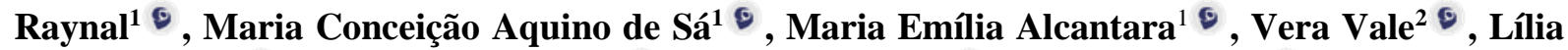

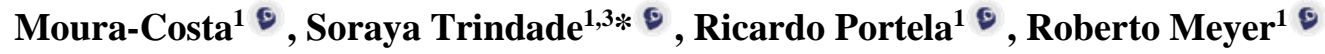 \\ ${ }^{I}$ Departamento de Biointeração, Laboratório de Imunologia e Biologia Molecular, Instituto de Ciências da Saúde (ICS), Universidade Federal \\ da Bahia (UFBA), Salvador, Bahia, Brasil. \\ ${ }^{2}$ Departamento de Física e Ciências da Terra, Universidade do Estado da Bahia (UNEB), Alagoinhas, Bahia, Brasil. \\ ${ }^{3}$ Departamento de Saúde, Universidade Estadual de Feira de Santana (UEFS), Feira de Santana, Bahia, Brasil. \\ *Autor para correspondência, E-mail: daniellevetlima@gmail.com.
}

Resumo. Corynebacterium pseudotuberculosis é o agente causador da linfadenite caseosa em pequenos ruminantes levando a formação de granulomas em linfonodos e órgãos. $\mathrm{O}$ papel dos mecanismos imunes inatos envolvidos na patogênese causada por esta bactéria ainda não foi totalmente elucidado e deve ser compreendido para o desenvolvimento racional de candidatos vacinais. O presente estudo avaliou a expressão de RNAm de IL1 $\beta$, TNF- $\alpha$, TLR2, TLR4 e TLR9 em ovinos infectados com uma linhagem de baixa virulência (T1) e imunizados com antígenos secretados desta linhagem e posteriormente desafiados com uma linhagem virulenta de $C$. pseudotuberculosis. Cinco ovinos foram inoculados com a dose $10^{9}$ UFC de uma linhagem de baixa virulência (T1) de C. pseudotuberculosis, cinco foram imunizados com $250 \mu \mathrm{g}$ de antígenos secretados em um meio quimicamente definido (MQD) e três animais foram utilizados para compor o grupo controle no qual receberam somente solução salina $0,09 \%$. Os animais foram desafiados com uma dose de $2 \times 10^{5}$ UFC de uma linhagem virulenta de C. pseudotuberculosis, e posteriormente necropsiados. Os animais do grupo controle após o desafio foram utilizados para compor o grupo de animais infectados. Os resultados demonstraram que houve uma expressão um pouco mais evidente de RNAm de TNF- $\alpha$ e dos TLRs 2, 4 e 9 nos animais do grupo T1 que não desenvolveram lesões, entretanto não foi estatisticamente significante. Todos os grupos foram capazes de influenciar na expressão de RNAm de IL1 $\beta$, TNF- $\alpha$, TLRs 2 , 4 e 9.

Palavras chave: linfadenite caseosa, resposta imune inata, TLR 2, 4 e 9.

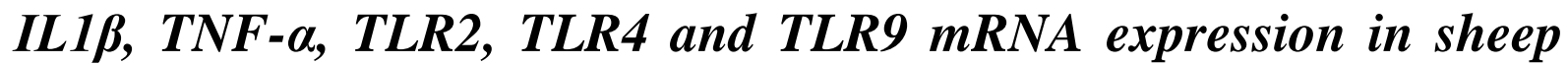 immunized with Corynebacterium pseudotuberculosis antigens}

\footnotetext{
Abstract. Corynebacterium pseudotuberculosis is the etiological agent of Caseous Lymphadenitis in small ruminants and causes granulomas in lymph nodes and organs. The role of innate immune mechanisms involved in the pathogenesis of this bacterium has not yet been completely elucidated and must be understood for the rational development of vaccine candidates. This study evaluated IL1 $\beta$, TNF- $\alpha$, TLR2, TLR4 and TLR9 mRNA expression in sheep infected with a low virulence strain (T1) and immunized with secreted antigens of T1 and later challenged with a virulent strain of $C$. pseudotuberculosis. Five sheep were inoculated with a dose of $109 \mathrm{CFU}$ of T1 (a low virulence strain of C. pseudotuberculosis), five were immunized with $250 \mu \mathrm{g}$ of secreted antigens in chemically defined medium (CDM) and three animals were used in the control group in which they received only $0.09 \%$ saline solution. All animals were challenged with a dose of $2 \times 10^{5} \mathrm{CFU}$ of a virulent $C$.
} 
pseudotuberculosis strain, and subsequently necropsied. Control group animals after challenge were used to compose the infected animal group. The results showed that there was slightly higher expression of TNF- $\alpha$, TLR2, TLR4 and TLR9 mRNA in animals from group T1, which did not develop lesions, however, it was not statistically significant. All groups influenced in the expression of IL1 $\beta$, TNF- $\alpha$, TLR2, TLR4 and TLR9 mRNA.

Keywords: caseous, lymphadenitis, innate immune response, TLR 2, 4 and 9

\section{Expresión de ARNm de IL1ß, TNF- $\alpha$, TLR2, TLR4 y TLR9 en ovinos inmunizados con antígenos de Corynebacterium pseudotuberculosis}

Resumen. Corynebacterium pseudotuberculosis es el agente etiológico de la linfadenitis
caseosa en pequeños rumiantes, y genera granulomas en los ganglios linfáticos y en los
órganos. El papel de los mecanismos inmunes innatos involucrados en la patogénesis de
esta bacteria aún no se ha aclarado por completo, y debe ser entendido para permitir el
desarrollo racional de vacunas candidatas. El presente estudio evaluó la expresión de
ARNm de IL1 $\beta$, TNF- $\alpha$, TLR2, TLR4 y TLR9 en ovinos infectados con cepa de baja
virulencia (T1) e inmunizados con antígenos secretados de esta cepa y luego desafiados
con cepa virulenta de $C$. pseudotuberculosis. Cinco ovinos fueron inoculados con la dosis
de 109 UFC de cepa de baja virulencia (T1) de $C$. pseudotuberculosis, cinco fueron
inmunizados con $250 \mu$ g de antígenos secretados en un medio químicamente definido
(MQD) y tres animales fueron utilizados para formar parte del grupo control en el que
recibieron solo solución salina 0,09\%. Los animales fueron desafiados con una dosis de
$2 x 10^{5}$ UFC de una cepa virulenta de $C$. pseudotuberculosis, y posteriormente fue realizada
la necropsia. Los animales del grupo control después del desafío fueron usados para
componer el grupo de animales infectados. Los resultados mostraron una expresión
ligeramente más alta de ARNm de TNF- $\alpha$, TLR2, TLR4 y TLR9 en los animales del grupo
T1, que no desarrollaron lesiones, sin embargo, no fue estadísticamente significativo. Todos
los grupos pudieron influir en la expresión de ARNm de IL1 $\beta$, TNF- $\alpha$, TLR2, TLR4 y TLR9.

Palabras clave: linfadenitis caseosa, respuesta inmune innata, TLR 2, 4 e 9

\section{Introdução}

A Linfadenite caseosa é uma doença granulomatosa de caráter crônico causado por Corynebcterium pseudotuberculosis $(C p)$, que acomete principalmente caprinos e ovinos (Fontaine \& Baird, 2008; Guimarães et al., 2011). A resposta imunológica do hospedeiro frente à infecção por $C p$ é bastante complexa, apresentando tanto caráter celular como humoral (Batey, 1986). Contudo, segundo Ayers (1977) e Brogden et al. (1985) essa resposta depende, predominantemente, da ativação celular. Estudos revelam que durante a infecção por este microrganismo há uma forte resposta humoral, apesar dessa resposta não ser capaz de eliminar a infecção (Fontaine et al., 2006).

O papel do sistema imune inato na infecção pelo $C p$ ainda não é bem compreendido. Todavia, já se sabe do envolvimento de citocinas pró-inflamatórias como IL-1 $\beta$, TNF- $\alpha$ e INF- y na fase inicial da infecção (Pépin et al., 1997; Stefańska et al., 2010). A ativação efetiva dessa resposta imune configurase em um melhor direcionamento para resposta imune adaptativa. Esta resposta pode ser feita pelo reconhecimento de padrões moleculares associados a patógenos (PAMPs), que são reconhecidos por receptores de reconhecimento padrão (PRRs) na superfície celular e em compartimentos endocíticos presentes nos macrófagos, monócitos e células dendríticas no hospedeiro (Stuart et al., 2012). Após o reconhecimento dos PAMPs, células dendríticas podem iniciar uma resposta imune adaptativa que consiste conjuntamente na produção de anticorpos pelos linfócitos $\mathrm{B}$ e ativação de linfócitos T. A geração de memória de linfócitos B e T é o objetivo da maioria das vacinas que pode estender a duração da resposta adaptativa durante o tempo de vida do indivíduo (Hajishengallis \& Lambris, 2011).

Uma das famílias de PRRs mais estudadas, os Toll Like Receptors (TLRs), reconhecem PAMPs de diferentes microrganismos como fungos, bactérias e vírus (Akira et al., 2006). Estudos in vitro e in vivo demonstram que os TLRs reconhecem componentes microbianos, estimulando a maturação de DCs e a 
produção de citocinas (Levitz \& Golenbock, 2012). Os TLR1, TLR2, TLR4, TLR5 e TLR6 são expressos na membrana plasmática, enquanto os TLR3, TLR7, TLR8 e TLR9 ocorrem em compartimentos endossômicos (Brinkmann et al., 2007). Ambos TLR2 e TLR4 já foram diretamente implicados no reconhecimento de micobactérias (Ferwerda et al., 2007; Jo, 2008; Simmons et al., 2010). Estudos têm demonstrado o envolvimento do TLR9 na modulação da resposta imune contra o $M$. tuberculosis e M. avium (Carvalho et al., 2011; Thirunavukkarasu et al., 2013). A variação dos padrões de expressão dos TLRs pode ser útil como potencial biomarcador para uma melhor compreensão do estado imunológico do hospedeiro (Plain et al., 2010; Thirunavukkarasu et al., 2013). Considerando o importante papel desempenhado pelos TLRs na imunidade inata que consiste no direcionamento da resposta imune adaptativa, este estudo teve como objetivo avaliar a resposta imune inata através da avaliação da expressão gênica de RNAm dos TLRs 2, 4 e 9 e das citocinas IL - $1 \beta$ e TNF- $\alpha$ de ovinos experimentalmente infectados e imunizados com antígenos secretados de $C p$ para uma melhor compreensão dos mecanismos imunológicos iniciais envolvidos na interação parasito hospedeiro.

\section{Material e métodos}

\section{Animais}

Os ovinos utilizados nos experimentos foram animais sem raça definida (SRD), com idade entre três e seis meses, ambos os sexos, com sorologia negativa para C. pseudotuberculosis. Os animais foram mantidos nas condições de criação semi-intensiva, na unidade experimental do Laboratório de Imunologia, em Salinas da Margarida, Bahia. Os animais foram examinados clinicamente antes e após a inoculação e acompanhados mensalmente ao longo dos 270 dias do experimento por um veterinário para inspeção visual e palpação dos diversos linfonodos superficiais.

\section{Grupos experimentais e amostras de linfonodos}

Foram utilizados três grupos de animais submetidos aos seguintes tratamentos: $O$ primeiro grupo (grupo MQD) com cinco animais recebeu $250 \mu \mathrm{g}$ do meio MQD mais 1,5 mg de saponina de Quillaja saponaria como adjuvante; o segundo grupo (grupo T1) também com cinco animais recebeu uma dose de $1 \times 10^{9}$ UFC por $\mathrm{mL}$ de uma linhagem de baixa virulência denominada T1 de C. pseudotuberculosis. O terceiro grupo (grupo controle) constituído por três animais recebeu somente solução salina a $0,09 \%$. A inoculação $(1 \mathrm{~mL})$ foi realizada por via subcutânea, na região da fossa paralombar direita. Com 60 dias o grupo MQD recebeu um reforço com a mesma dose e volume. Após 180 dias do início da primeira inoculação, os animais de todos os grupos foram desafiados com uma linhagem de alta virulência de $C$. pseudotuberculosis na dose de $2 \times 10^{5}$ UFC $(1 \mathrm{~mL})$ na região inguinal direita por via intradérmica. Os animais do grupo controle após o desafio foram utilizados para compor o grupo de animais experimentalmente infectados (grupo VD57). Quinze dias após o desafio os animais foram submetidos a uma cirurgia para remoção do linfonodo inguinal direito. Os animais foram anestesiados com os seguintes anestésicos: ketamina $(2 \mathrm{mg} / \mathrm{kg})$; xilazina $0,1 \mathrm{mg} / \mathrm{kg}$ e lidocaína $(0,2 \mathrm{mg} / \mathrm{kg})$. Os linfonodos coletados $(30 \mathrm{mg})$ foram colocados imediatamente em $1 \mathrm{~mL}$ de RNA later ${ }^{\circledR}$ (RNA Stabilization Reagent). Três meses após o desafio os animais foram abatidos no matadouro frigorifico Baby bode em Feira de Santana através do método humanitário de atordoamento por eletronarcose. Os órgãos internos e linfonodos foram separados para exame anatomopatológico. Os linfonodos inguinais esquerdo foram também submetidos imediatamente a $1 \mathrm{~mL}$ de RNA later $^{\circledR}$ e depois congelados a $-80^{\circ} \mathrm{C}$ para posteriormente serem utilizados para extração de RNA.

\section{Linhagens bacterianas}

Neste experimento foram utilizadas duas linhagens bacterianas provenientes da Coleção de Microrganismos do Instituto de Ciências da Saúde da UFBA, conforme descrito por Moura-Costa et al. (2008). A linhagem codificada como T1 foi isolada a partir de linfonodo caprino com lesão, na região de Santa Luz na Bahia. Esta linhagem foi considerada naturalmente atenuada por apresentar hemólise sinérgica com Rhodococcus equi menos intensa que as demais, assim como por não causar o óbito de camundongos BALB/c, em dose de $10^{7} \mathrm{UFC}$, após inoculação experimental e apenas induzir a formação de lesões discretas. A confirmação da identificação desta cepa foi realizada através de coloração de Gram, morfologia colonial, hemólise sinérgica com R. equi, produção de urease e catalase, com posterior validação bioquímica pelo kit API Coryne (BioMérieux). 
A linhagem selvagem empregada no experimento foi originalmente isolada na região de Juazeiro, Estado da Bahia, a partir de material de linfonodo de caprino, sendo catalogada como VD57. Esta linhagem foi submetida ao mesmo processo de identificação utilizado para a cepa T1. As linhagens bacterianas usadas neste experimento, assim como as demais amostras de C. pseudotuberculosis isoladas a partir de granulomas de ovinos foram mantidas em glicerol e armazenadas a $-70^{\circ} \mathrm{C}$.

\section{Suspensão bacteriana da linhagem T1 e VD57}

Uma colônia da linhagem T1 de C. pseudotuberculosis cultivada em ágar BHI (48h a $37^{\circ} \mathrm{C}$ ) foi repicada para $5 \mathrm{~mL}$ de caldo BHI. Após $48 \mathrm{~h}$ a $37^{\circ} \mathrm{C}$, estes $5 \mathrm{~mL}$ de cultura foram repicados para 250 $\mathrm{mL}$ de caldo BHI e mantidos a $37^{\circ} \mathrm{C}$ por $72 \mathrm{~h}$. Em seguida, a massa bacteriana foi centrifugada em centrífuga refrigerada por $30 \mathrm{~min}$ a $8.000 \mathrm{rpm}$. A massa bacteriana foi ressuspensa em $10 \mathrm{~mL}$ de solução salina estéril. Foi realizada a contagem bacteriana realizando-se diluições decimais em PBS, sendo estas diluições semeadas por disseminação em placas da ágar BHI. A contagem de colônias foi feita após $48 \mathrm{~h}$ de incubação a $37^{\circ} \mathrm{C}$. A concentração foi ajustada para dose de $1 \times 10^{9} \mathrm{UFC} / \mathrm{mL}$ para ser utilizada no grupo T1 no tempo zero. Foi realizada coloração de Gram, assim como semeadura em ágar BHI, ágar sangue e ágar Sabouraud para verificar a ausência de contaminantes. O mesmo procedimento foi realizado para obtenção da dose de $2 \times 10^{5} \mathrm{UFC} / \mathrm{mL}$ da linhagem de alta virulência VD 57 que foi utilizada no momento do desafio dos animais.

\section{Antígenos secretados em meio sintético quimicamente definido obtidos da linhagem T1}

As bactérias foram ativadas em $5 \mathrm{~mL}$ de caldo BHI por $48 \mathrm{~h}$ até apresentarem crescimento satisfatório, sendo então centrifugadas por 15 minutos a $3000 \mathrm{~g}$. O sedimento bacteriano foi ressuspenso em PBS e adicionado $1.000 \mathrm{~mL}$ do meio sintético quimicamente definido, conforme descrito por Moura-Costa (2002). A cultura foi mantida a $37^{\circ} \mathrm{C}$ por 72 horas, sendo então centrifugada a $10000 \mathrm{~g}$ por 30 minutos a $4^{\circ} \mathrm{C}$. O sobrenadante foi filtrado a vácuo em membrana Millipore $0,22 \mu \mathrm{m}$, e em seguida concentrado através de liofilização. O material liofilizado foi ressuspenso em PBS e dializado por $48 \mathrm{~h}$ em membrana de $3 \mathrm{Kda}$, sendo então a determinação do seu conteúdo proteico realizada com kit comercial baseado na metodologia de Lowry (Kit Bio-Rad), tendo sido usado soro albumina bovina, bovina como padrão. Foi obtida, de acordo com este método, uma concentração proteica de $1,31 \mathrm{mg} / \mathrm{mL}$.

\section{Necropsia}

Três meses após o desafio, os animais foram encaminhados para o abatedouro frigorífico Baby Bode, no município de Feira de Santana, Bahia, onde foram abatidos pelo método humanitário de atordoamento por eletro narcose. Os órgãos e linfonodos foram separados para inspeção. Foi dada atenção especial aos linfonodos, pulmões, fígados e baços. Outros órgãos como rins também foram inspecionados. Os tecidos que apresentaram lesões foram acondicionados assepticamente em coletores estéreis para posterior identificação bacteriana. Os linfonodos inguinais do lado esquerdo foram coletados e adicionados um $1 \mathrm{~mL}$ de RNA later ${ }^{\circledR}$ e depois congelados a $-80^{\circ} \mathrm{C}$ para posteriormente serem utilizados na quantificação de RNAm pela técnica de PCR em tempo real.

\section{Identificação bacteriana nas lesões}

As amostras foram analisadas no laboratório de microbiologia do Instituto de Ciências da Saúde da UFBA com presença de material caseoso sugestivo de infecção por $C$. pseudotuberculosis pela morfologia colonial, coloração de Gram, prova da catalase, prova da urease, fermentação de carboidratos: glicose, lactose, sacarose e manose. Foi realizada hemólise sinérgica de algumas das amostras coletadas e feita a comparação com o padrão hemolítico das duas linhagens usadas no experimento (T1 e VD57).

\section{Extração de RNAm ovino}

O kit utilizado para a extração de RNAm ovino foi RNeasy Minikit/Qiagen. As amostras (30 mg) foram descongeladas e cada amostra foi colocada em tubos com Microbeats. Em cada tubo adicionouse $600 \mu \mathrm{L}$ do tampão de lise RLT e em seguida homogeneizados por 3 minutos no SpeedMill. Os sobrenadantes foram transferidos para outros micros tubos onde foram centrifugados durante 3 minutos 
na velocidade de $16.000 \mathrm{x}$ g. Adicionou-se $600 \mu \mathrm{L}$ de etanol $70 \%$ ao sobrenadante e misturou-se com a pipeta. Transferiu-se a amostra para uma coluna de sílica (RNeasy Mini spin) colocada sobre um tubo coletor de $2 \mathrm{~mL}$ e centrifugou-se 30 segundos a $10.000 \mathrm{x}$ g. Descartou-se o filtrado e adicionou-se 700 $\mu \mathrm{L}$ de tampão RW1 sendo centrifugado por 30 segundos a $10000 \mathrm{x}$ g. A coluna foi adicionada em um novo tubo coletor e adicionados $500 \mu \mathrm{L}$ de tampão RPE sendo novamente centrifugados por mais 30 segundos a $10.000 \mathrm{x} \mathrm{g}$; o filtrado foi descartado e a coluna foi colocada em micro tubo onde foram adicionados $45 \mu \mathrm{L}$ de água livre de RNAse diretamente em cima da membrana de sílica sendo posteriormente centrifugada por 1 minuto a 10.000 x g. Depois a coluna (RNeasy Mini spin) foi descartada e o conteúdo estocado em freezer de $-80^{\circ} \mathrm{C}$.

\section{Produção de cDNA}

Para a produção de cDNA foi utilizado o kit da Invitrogen. Para cada reação de produção de cDNA foram adicionados: no mix 1: $\mathrm{H}_{2} \mathrm{O}$ livre de RNAse 6,5 $\mu \mathrm{L}$, Hexâmeros aleatórios (random hexamers) $(0,3 \mu \mathrm{g} / \mu \mathrm{l})$ no volume de $1 \mu \mathrm{L}$; dNTPs $(4 \times 2,5 \mathrm{mM}) 5 \mu \mathrm{L}$ e o material da extração contendo RNAm no volume de $3,75 \mu \mathrm{L}$. Esta mistura foi colocada em um termociclador ajustado a $95^{\circ} \mathrm{C}$ por 5 minutos, para separação das fitas de RNA presentes na solução. No mix 2: tampão de síntese da primeira fita

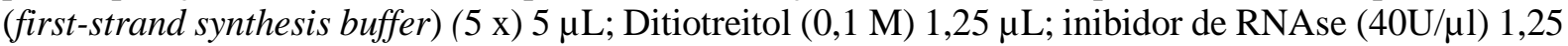
$\mu \mathrm{L}$ e a enzima Superscript III Reverse Transcriptase (200U/ $\mu$ l) $1,25 \mu \mathrm{L}$. Os tubos foram retirados do termocilador e colocados imediatamente em uma rack de gelo e adicionado o mix $2(8,75 \mu \mathrm{L})$. O tubo foi recolocado no termociclador e a extensão dos hexâmeros foi feita da seguinte maneira: 10 minutos a $25^{\circ} \mathrm{C}, 30$ minutos a $50^{\circ} \mathrm{C}, 15$ minutos a $53^{\circ} \mathrm{C}$ e 10 minutos a $55^{\circ} \mathrm{C}$. A transcriptase reversa foi a seguir inativada com a incubação dos tubos a $70^{\circ} \mathrm{C}$ por 15 minutos. $\mathrm{O}$ cDNA produzido foi mantido a $-80^{\circ} \mathrm{C}$ até o momento da realização das qPCR.

\section{PCR em tempo real- $q P C R$}

As reações foram realizadas com um volume final de $25 \mu \mathrm{L}$ Para cada reação: $\mathrm{H}_{2} \mathrm{O}$ livre de RNAse 7,4 $\mu \mathrm{L}$; Power SYBR Green Master Mix (2X) (Applied Biosystems) 12,5 $\mu \mathrm{L}$; Albumina Sérica Bovina $(1 \mathrm{mg} / \mathrm{ml}) 1 \mu \mathrm{L} ; 0,75 \mu \mathrm{L}$ das soluções $10 \mu \mathrm{M}$ dos iniciadores (primers) senso (forward) e antissenso (reverse); a enzima Platinum Taq Polymerase $(5 \mathrm{U} / \mu \mathrm{l}) 0,1 \mu \mathrm{L}$ e $2,5 \mu \mathrm{L}$ de cDNA. Os iniciadores (primers) utilizados são apresentados na tabela 1. Os pares de primers foram desenhados com a ferramenta "Primer Quest" da página Integrated DNA Technologies, IDT, disponível em http://www.idtdna.com/site. A amplificação dos alvos foi realizada no termociclador ABI Prism 7500 (Applied Biosystems), sob as seguintes condições de tempo e temperatura: desnaturação inicial por 10 minutos a $95^{\circ} \mathrm{C}$, seguida de 45 ciclos de desnaturação por 20 segundos a $94^{\circ} \mathrm{C}$ e anelamento por 60 segundos a $64^{\circ} \mathrm{C}$. O resultado de cada qPCR foi avaliado mediante análise da curva de dissociação (melting curve). Não foi realizado um teste de validação com os produtos das qPCR, ou seja, sequenciamento dos amplicons obtidos.

Tabela 1. Iniciadores (primers) utilizados no PCR em tempo real

\begin{tabular}{lccc}
\hline Nome & Forward & Reverse & Tamanho bp \\
\hline IL-1 $\beta$ (Budhia et el., 2006) & CGAACATGTCTTCCGTGATG & TCTCTGTCCTGGAGTTTGCAT & 143 \\
TNF- $\alpha$ (Wang et al. 2012) & ACACCATGAGCACCAAAAGC & AGGCACAAGCAACTTCTGGA & 103 \\
TLR-2 (Wang et al. 2012) & CAAGAGGAAGCCCAGGAAG & TGGACCATGAGGTTCTCCA & 102 \\
TLR-4 (Wang et al. 2012) & TGCTGGCTGCAAAAAGTATG & CCCTGTAGTGAAGGCAGAGC & 149 \\
TLR-9 (Chang et al. 2009) & CCCTGGAGAAGCTGGACAT & GACAGGTCCACGAAGAGCAG & 175 \\
GAPDH (Zang et al. 2011) & GGTGATGCTGGTGCTGAGTA & TCATAAGTCCCTCCACGATG & 265 \\
\hline
\end{tabular}

\section{Quantificação relativa do RNAm}

Para a quantificação relativa foi utilizada uma amostra que se apresentou mais forte no qPCR. A partir dessa amostra foram feitas diluições seriadas para os cálculos da quantificação. A partir deste cDNA foram preparadas seis diluições seriadas com água destilada de grau PCR, variando de 10-1 a 106. Para cada uma das diluições citadas, foram realizadas seis qPCR usando-se primers para os cinco genes estudados (Tabela 1) mais um par de primers para o gene GAPDH usado como normalizador no 
presente estudo. A cada um dos 6 tubos contendo cDNA não diluído foi atribuído um número fictício de 10.000.000 (dez milhões) de moléculas do respectivo RNAm, correspondendo 1.000.000 de moléculas ao tubo com diluição 10-1, 100.000 moléculas ao tubo com diluição 10-2, 10.000 moléculas ao tubo com diluição 10-3, e assim por diante, até o número de 10 moléculas no tubo contendo a diluição 10-6. Depois de realizadas as corridas de qPCR, foi aplicada a análise de regressão linear para gerar uma curva de calibração para cada um dos genes, correlacionando o logaritmo do número de moléculas em ordenadas e o valor do $\mathrm{Ct}$ (cycle threshold) em abscissas. Desta forma, foram obtidos os coeficientes angulares e lineares para cada uma das seis retas. Estas retas foram usadas para as quantificações relativas de DNA (e, por extensão, de RNAm) nas demais corridas de PCR em tempo real da seguinte maneira: para cada um dos cinco genes estudados, com base no valor do $\mathrm{Ct}$ verificado na respectiva qPCR, foi calculado um fator de quantificação (correspondente ao número de moléculas de RNAm), determinado assim: fator de quantificação $=10 \mathrm{~W}$, onde $\mathrm{w}=$ [coeficiente linear $-(\mathrm{Ct} x$ coeficiente angular)]. Dividindo-se os valores dos fatores de quantificação dos diferentes genes pelos respectivos valores do gene normalizador, obtêm-se as quantidades relativas de expressão dos primeiros.

\section{Análise estatística}

Inicialmente, foi testada a normalidade na distribuição dos dados pelo teste de Kolmogorov-Smirnov. Observou-se distribuição normal em todos os grupos, exceto para o ponto 90 dias para IL-1 $\beta$. Assim, para esta variável, empregou-se o teste não paramétrico de Kruskall-wallis. Para os demais, foi empregado o teste ANOVA com o pós-hoc de Tukey.

\section{Resultados}

\section{Expressão do RNAm das citocinas $I L-1 \beta, T N F-\alpha$}

A expressão do RNAm de IL-1 $1 \beta$ e TNF- $\alpha$ em tecidos de linfonodos inguinais de ovinos infectados e imunizados e posteriormente desafiados com uma cepa virulenta de $C$. pseudotuberculosis estão apresentados na figura 1. O que podemos observar inicialmente é que a expressão de RNAm de IL-1 $\beta$ foi similar entre os grupos não acarretando diferenças estatisticamente significante durante os dois tempos estudados. Ao avaliarmos a expressão de TNF- $\alpha$, encontramos uma expressão mais elevada com 15 dias pós-desafio em todos os grupos, entretanto esta diferença somente foi estatisticamente significativa nos grupos MQD e T1 quando comparado ao tempo de 90 dias $(\mathrm{P}>0,05)$.
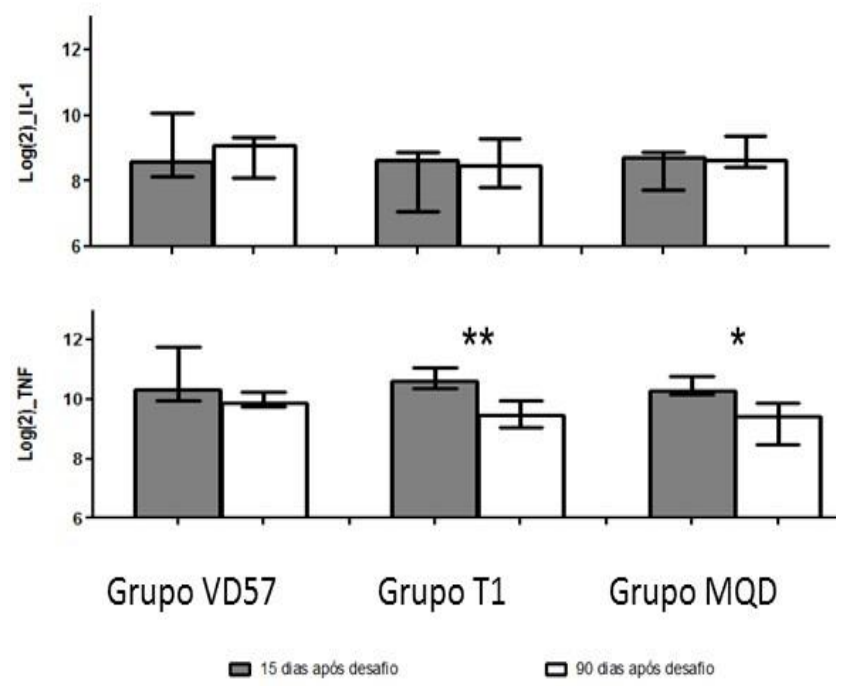

Figura 1. Expressão de RNAm de TNF- $\alpha$, e IL-1 $\beta$ em linfonodos inguinais de ovinos após o desafio com uma cepa virulenta de $C$. pseudotuberculosis em dois momentos: com 15 e 90 dias pós-desafio. Grupo MQD $(n=5)$ - animais inoculados com imunógeno constituído de $250 \mu \mathrm{g}$ de antígeno MQD associado a 1,5 mg de saponina como adjuvante; Grupo T1 $(n=5)$ - animais inoculados com 1x10 ${ }^{9}$ UFC de $C$. pseudotuberculosis da cepa de baixa virulência; Grupo VD57 $(\mathrm{n}=3)$ - animais inoculados somente com $2 \times 10^{5}$ UFC da cepa virulenta (VD57) de C. pseudotuberculosis. Asteriscos indicam significância: $* *=(\mathrm{P}<0,01) \mathrm{e}^{*}=(\mathrm{P}<0,05)$. 
A figura 2 mostra um gráfico de correlação onde as retas indicam a tendência dos dados. Os resultados foram estratificados de acordo com o grupo, tempo e ocorrência de lesões nos animais. O que podemos observar é que existe uma tendência dos animais que não desenvolveram lesões (linha preta e bolinha preta) em apresentarem expressão do RNAm de TNF- $\alpha$ mais evidente nos animais dos grupos MQD e T1. No grupo VD57 a expressão de TNF- $\alpha$ foi mais acentuada nos animais que desenvolveram lesões (linha tracejada e bolinha branca). Os animais do grupo MQD que não apresentaram lesões (linha preta e bolinha preta) tiveram uma expressão mais elevada de RNAm de IL-1 $\beta$ quando comparado aos animais que apresentaram lesões. Entretanto no grupo T1 houve uma tendência dos animais que

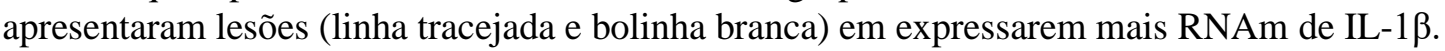

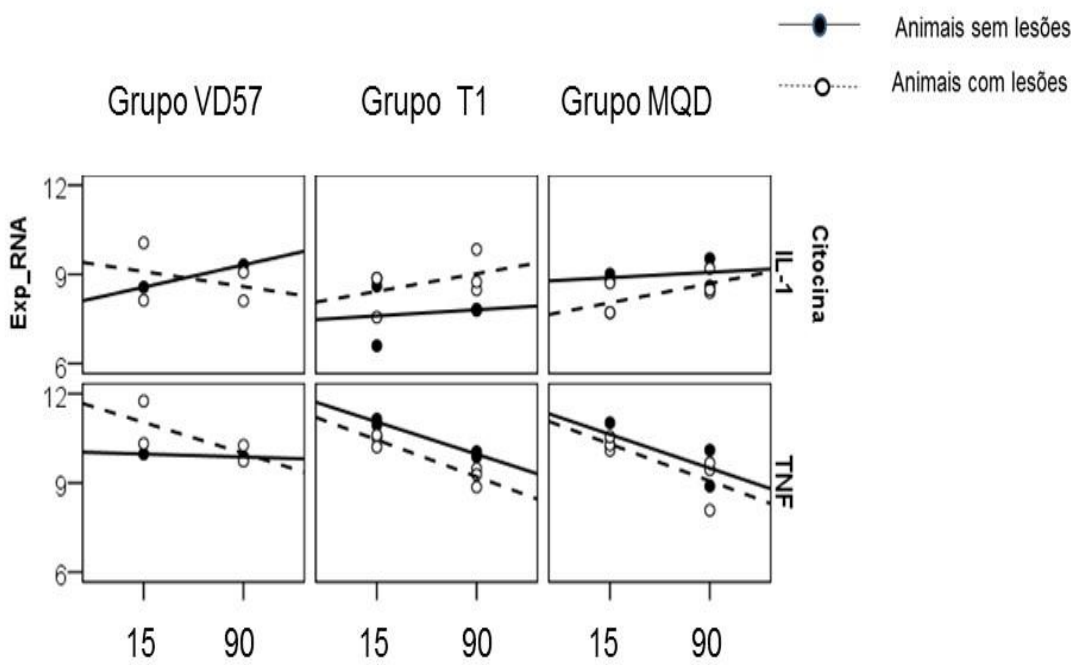

Dias pós -desafio

Figura 2. Correlação entre a expressão de RNAm das citocinas TNF- $\alpha$, e IL-1 $\beta$ em linfonodos inguinais de ovinos após o desafio com uma cepa de alta virulência de C. pseudotuberculosis e o surgimento de lesões de linfadenite caseosa. Grupo MQD $(n=5)$ - animais inoculados com imunógeno constituído de $250 \mu \mathrm{g}$ de antígeno MQD associado a 1,5 mg de saponina como adjuvante; Grupo T1 $(n=5)$ - animais inoculados com $1 \times 10^{9}$ UFC de $C$. pseudotuberculosis da cepa de baixa virulência T1; Grupo VD57 ( $\mathrm{n}=3)$ - animais inoculados somente com $2 \times 10^{5}$ UFC da cepa virulenta (VD57) de C. pseudotuberculosis.

\section{Expressão de RNAm de TLR2,4 e 9}

O presente trabalho avaliou a expressão do RNAm dos TLRs 2,4 e 9 em linfonodos inguinais dos animais estudados. Os resultados mostram que no grupo T1 houve diferenças estatisticamente significantes quando comparamos à expressão dos TLR 2,4 e 9 entre os tempos 15 e 90 dias pós-desafio $(\mathrm{P}<0,05)$ (Figura 3). No grupo MQD também ocorreu uma expressão de RNAm com 15 dias mais elevada em comparação com 90 dias, entretanto esta diferença não foi estatisticamente significante. No grupo VD57 não houve diferença estatisticamente significante na expressão do RNAm dos TLRs entre os tempos e em comparação com os demais grupos.

Ao analisarmos a correlação entre a expressão de RNAm dos TLRs 2,4 e 9 e ocorrência de lesões, o que podemos observar é que existe uma propensão dos animais do grupo T1 que não desenvolveram lesões (linha preta e bolinha preta) em apresentarem níveis mais elevados de expressão do RNAm dos TLRs 2,4 e 9 (Figura 4). Os animais do grupo VD57 que desenvolveram lesões (linha tracejada e bolinha branca) apresentaram uma expressão mais elevada dos TLRs sendo esta evidência foi mais pronunciada com 15 dias pós-desafio. O que podemos observar no grupo MQD é que a expressão dos TLRs 2,4 e 9 foi similar entre os animais que não desenvolveram lesões e os que desenvolveram tendo em vista ao que encontramos no gráfico de regressão linear onde as retas estão bem próximas em todos os TLRs analisados. 

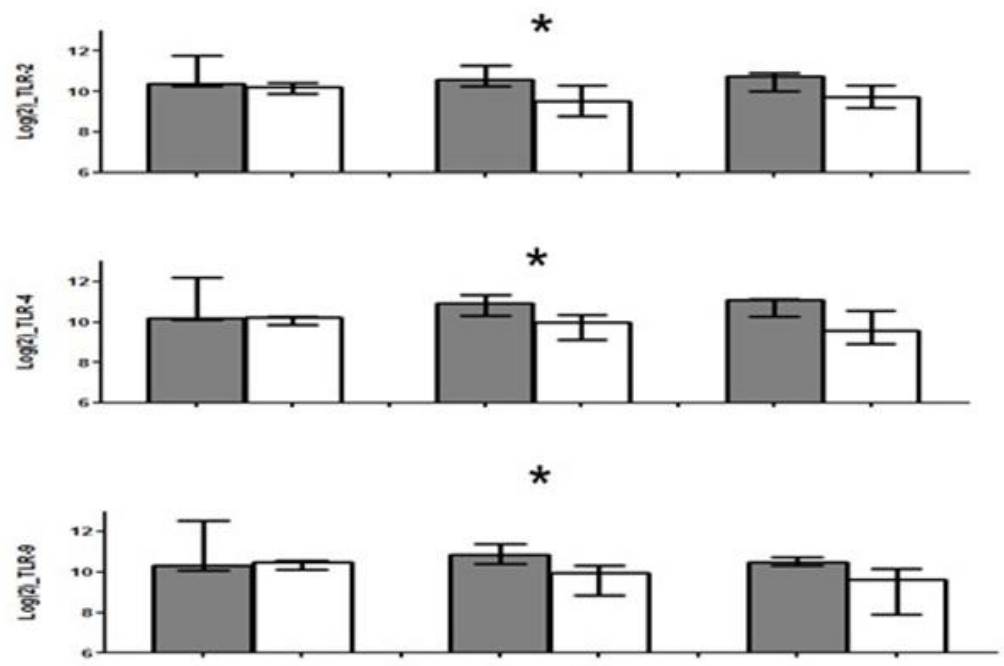

\section{Grupo VD57 Grupo T1 Grupo MQD \\ 口 15 das após desafio \\ 口 90 dias após desano}

Figura 3. Expressão de RNAm dos TLRs 2,4 e 9 em linfonodos inguinais de ovinos após o desafio com uma cepa de alta virulência de $C$.pseudotuberculosis em dois momentos: com 15 e 90 dias pós-desafio. Grupo MQD $(n=5)$ - animais inoculados com imunógeno constituído de $250 \mu \mathrm{g}$ de antígeno MQD associado a 1,5 mg de saponina como adjuvante; Grupo T1 $(n=5)$ - animais inoculados com $1 \times 10^{9}$ UFC de C. pseudotuberculosis da cepa de baixa virulência T1; Grupo VD57 $(\mathrm{n}=3)$ - animais inoculados somente com $2 \times 10^{5}$ UFC da cepa virulenta (VD57) de C. pseudotuberculosis. Asteriscos indicam significância: * $=(\mathrm{P}<0,05)$.

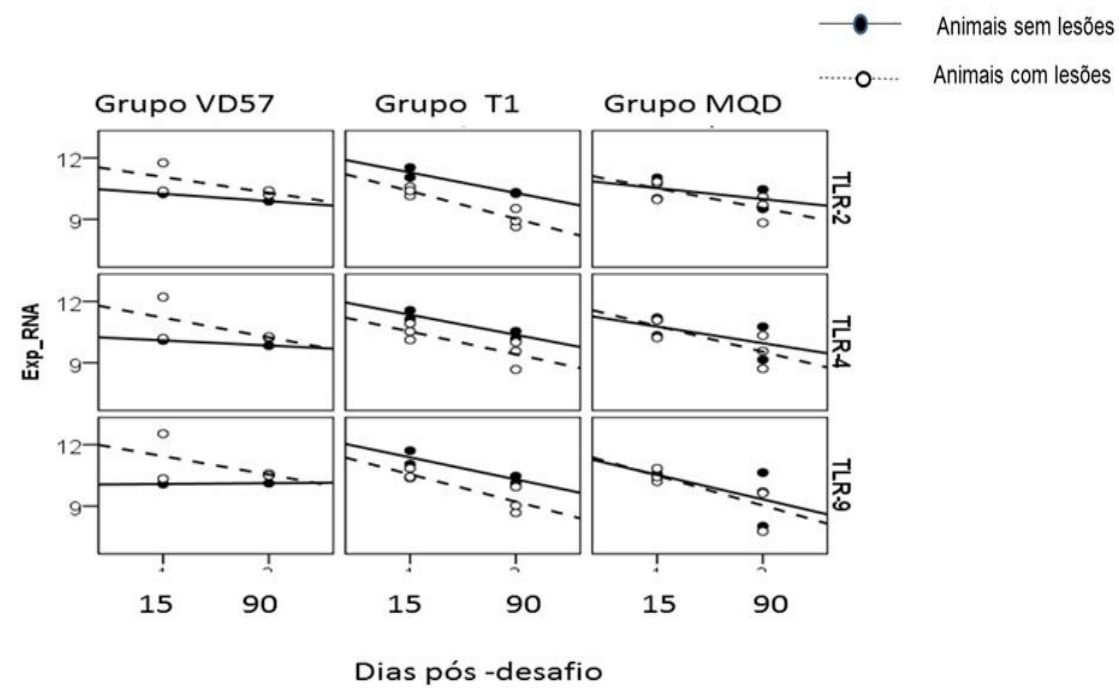

Figura 4. Correlação entre a expressão de RNAm dos TLRs 2,4 e 9 em linfonodos inguinais de ovinos após o desafio com uma cepa de alta virulência de C.pseudotuberculosis e o surgimento de lesões de linfadenite caseosa. Grupo MQD $(n=5)$ - animais inoculados com imunógeno constituído de $250 \mu \mathrm{g}$ de antígeno MQD associado a 1,5 mg de saponina como adjuvante; Grupo T1 $(n=5)$ - animais inoculados com $1 \times 10^{9}$ UFC de C. pseudotuberculosis da cepa de baixa virulência T1; Grupo VD57 $(\mathrm{n}=3)$ - animais inoculados somente com 2x10 $0^{5}$ UFC da cepa virulenta (VD57) de C. pseudotuberculosis.

\section{Discussão}

O êxito para o desenvolvimento de candidatos vacinais contra bactérias intracelulares depende da ativação efetiva tanto de uma resposta humoral como celular. A análise dos mecanismos da resposta imune inata é necessária para o direcionamento de tais respostas, sendo um importante passo para a concepção de vacinas. Estudos têm relatado o envolvimento dos TLRs em infecções com $M$. tuberculosis e M. avium. A importância destes receptores é devida principalmente à ativação e regulação 
de quimiocinas, citocinas e moléculas co-estimulatórias que irão atuar na resolução da infecção como também no direcionamento de uma resposta imune adaptativa. Diante desta constatação, nós analisamos pela técnica de PCR em tempo real a expressão de RNAm das citocinas pró-inflamatórias IL-1 $\beta$ e TNF$\alpha$, assim como dos receptores TLRS 2,4 e 9 em linfonodos inguinais de ovinos imunizados e posteriormente desafiados com uma linhagem de alta virulência de $C$. pseudotuberculosis. Os resultados obtidos com a expressão de IL-1 $\beta$ foram similares entre os grupos e durante os dois tempos estudados. Entretanto, os animais do grupo MQD que não apresentaram lesões tiveram uma expressão mais acentuada desta citocina. A IL-1 é uma potente citocina pró-inflamatória necessária em diversos processos patogênicos. A sua presença é importante para a geração de uma resposta imune adequada do hospedeiro contra infecções tais como pelo M. tuberculosis e outras bactérias intracelulares (Juffermans et al., 2000; Mayer-Barber et al., 2010).

Ao analisarmos a expressão de TNF- $\alpha$ observamos que houve diferenças na expressão desta citocina nos grupos T1 e MQD entre os dois tempos estudados. Podemos sugerir que os imunógenos utilizados influenciaram nos mecanismos imunológicos de ativação desta citocina, visto que o mesmo não ocorreu com o grupo VD57 que foi inoculado somente com uma linhagem virulenta. No grupo VD57 a expressão de TNF- $\alpha$ foi similar nos dois tempos, sugerindo uma multiplicação constante de bactérias no local de inoculação, o que levaria a uma expressão mais duradoura de TNF- $\alpha$. Ao avaliarmos a correlação da expressão desta citocina e o surgimento de lesões observamos que ocorreu uma tendência de os animais que não desenvolveram lesões em apresentarem uma expressão de TNF- $\alpha$ mais elevada no grupo T1 e no grupo MQD, embora não tenha sido constatado no presente estudo se uma maior expressão de TNF$\alpha$ refletiria em uma maior produção desta citocina tendo em vista que em outros trabalhos a produção elevada de TNF- $\alpha$ esteve associada principalmente com a conformação do granuloma contribuindo assim para contenção da bactéria evitando sua disseminação (Pépin et al., 1997). O TNF- $\alpha$ é produzido principalmente por macrófagos na fase precoce da infecção, o que é essencial para geração de resistência (Lan et al., 1998). Em um estudo para avaliar o papel do TNF- $\alpha$ na infecção por M. tuberculosis, pesquisadores administraram doses desta citocina em camundongos infectados com esta bactéria e observaram que os mesmos melhoravam significativamente (Kaneko et al., 1999; Mootoo et al., 2009). Pépin et al. (1997) afirmaram em um estudo realizado com diferentes linhagens de $C$. pseudotuberculosis, tanto virulentas como atenuadas, que a presença do TNF- $\alpha$ nos linfonodos drenantes foi elevada na primeira fase da infecção e que esta diminui com a cronicidade da doença.

No presente estudo, foi realizada a detecção da expressão dos TLR2, 4 e 9 para um melhor entendimento dos mecanismos envolvidos na resposta inata frente à infecção por C. pseudotuberculosis. Trata-se de uma iniciativa ainda não apresentada na pesquisa da linfadenite caseosa dos ovinos. Houve expressão de TLR 2, 4 e 9 em todos os grupos, não havendo diferenças entre os imunógenos e o grupo VD57. Entretanto, observamos que os animais do grupo T1 e MQD apresentaram uma maior expressão desses receptores com 15 dias pós-desafio. Podemos supor que devido os animais do grupo T1 e do grupo MQD terem sido inoculados com uma linhagem viva e com antígenos secretados, respectivamente, esses animais tiveram seus mecanismos imunológicos inatos ativados levando a um direcionamento mais eficaz para uma resposta imune adaptativa. Os resultados também mostraram que os animais do grupo T1 que tiveram uma maior expressão dos TLRs foram também os que não desenvolveram lesões. Esses dados com o grupo T1 podem estar associados a uma reposta imunomodulatória para controle da enfermidade, o que é essencial para o desenvolvimento de uma vacina. Em um estudo recente, macrófagos de camundongos infectados com Mycobacterium indicus pranii, uma micobatéria não patogênica que tem sido utilizada para o desenvolvimento de vacinas contra a tuberculose, responderam com a ativação de TLR2 mostrando essa bactéria um bom indutor da resposta imune inata (Pandey et al., 2012). O TLR2 forma heterodímeros com TLR1 ou TLR6 (Kleinnijenhuis et al., 2011). Esses heterodímeros reconhecem vários componentes da parede celular de micobactérias como glicolipídios (lipoarabinomanana e lipomanana), peptídioglicano e lipoproteínas (Kleinnijenhuis et al., 2011; Tapping \& Tobias, 2003). Acredita-se que o TLR2 é importante no início do desenvolvimento da resposta imune inata do hospedeiro contra o $M$. tuberculosis pela estimulação da produção de TNF- $\alpha$ pelos macrófagos (Underhill et al., 1999). Animais experimentalmente infectados com M.avium ssp. Paratuberculosis, agente causador da doença de Johne's, em bovinos apresentaram níveis mais altos de TLR2 na fase precoce da doença. Neste trabalho os autores sugerem 
o uso desse receptor como uma ferramenta para a previsão do estado de infecção em animais expostos a esta enfermidade (Thirunavukkarasu et al., 2013).

Um granuloma é uma característica fisiopatológica induzida pelo C. pseudotuberculosis como também por infecções por micobactérias configurando-se uma resposta imune para contenção do processo infeccioso. Estudos com micobactérias demonstraram que os receptores TLR2 e TLR9 estão envolvidos na manutenção da resposta granulomatosa durante as infecções por $M$. tuberculosis e $M$. avium em camundongos. Animais nocautes para TLR2 ou TLR9 apresentam um maior número de granulomas em diversos órgãos. Além disso, foi detectada uma redução do número de macrófagos, células epitelióides e de linfócitos no granuloma desses animais (Carvalho et al., 2011; Ito et al., 2007). O receptor TLR9 reconhece motivos CpG não metilados em DNA bacterianos e virais. Estudos in vitro mostraram que a indução para a produção de IL-12 por células dendríticas infectadas com M.tuberculosis foi dependente de TLR9 (Bafica et al., 2005; Pompei et al., 2007). Experimentos in vivo com camundongos deficientes para TLR9 e infectados com altas doses de $M$. tuberculosis não sobreviveram quando comparados aos animais normais (Bafica et al., 2005). O papel do TLR4 no reconhecimento de micobactérias ainda não foi bem esclarecido (Kleinnijenhuis et al., 2011). Esse receptor é ativado por proteínas de choque térmico 60/65 do M. tuberculosis (Bulut et al., 2005). Uma vez ativado, o TLR4 induz a produção de citocinas como TNF- $\alpha$ através de uma cascata de sinalização celular. Em um trabalho, macrófagos de camundongos nocaute para TLR4 apresentaram menor produção de TNF- $\alpha$ quando infectados com $M$. tuberculosis, e estes desenvolveram lesões em diversos órgãos como pulmões, fígado, e rins (Abel et al., 2002). Em outro estudo, macrófagos de camundongos nocaute para TLR4 infectados com Mycobacterium avium subsp. Paratuberculosis produziam menos IL-1 $\beta$ (Ferwerda et al., 2007). Ovinos que apresentavam mutação no gene do TLR4 tiveram maior susceptibilidade para essa bactéria (Bhide et al., 2009).

Um melhor entendimento dos mecanismos inatos frente à infecção pelo C.pseudotuberculosis é essencial para o desenvolvimento de vacinas. Os dados obtidos no presente trabalho são preliminares e mais estudos devem ser realizados com a linhagem de baixa virulência (T1) e com antígeno MQD, tendo em vista que ambos ativaram os TLRs de modo diferente ao grupo VD57 sugerindo o possível envolvimento desses imunógenos na ativação mais rápida de uma resposta imune adaptativa. Os resultados encontrados com a expressão gênica de RNAm de TNF- $\alpha$, e os TLRs 2, 4 e 9 podem estar associados com direcionamento de uma reposta imunomodulatória em animais inoculados com a linhagem de baixa virulência (T1) e os seus antígenos secretados. Os dados aqui apresentados são importantes para traduzir o conhecimento adquirido em novas estratégias de trabalho para uma melhor compreensão dos mecanismos inatos envolvidos contra a infecção pelo C. pseudotuberculosis, uma vez que, tais mecanismos ainda não foram bem elucidados, mas que são cruciais para o desenvolvimento de imunógenos contra essa enfermidade.

\section{Referências bibliográficas}

Abel, B., Thieblemont, N., Quesniaux, V. J. F., Brown, N., Mpagi, J., Miyake, K. \& Ryffel, B. (2002). Toll-like receptor 4 expression is required to control chronic Mycobacterium tuberculosis infection in mice. The Journal of Immunology, 169(6):3155-3162.

Akira, S., Uematsu, S. \& Takeuchi, O. (2006). Pathogen recognition and innate immunity. Cell, 124(4):783-801.

Ayers, L. (1977). Caseous lymphadenitis in goats and sheep: review of diagnosis, pathogenesis, and immunity. Journal of the American Veterinary Medical Association, 171(12):1251-1254.

Bafica, A., Scanga, C. A., Feng, C. G., Leifer, C., Cheever, A. \& Sher, A. (2005). TLR9 regulates Th1 responses and cooperates with TLR2 in mediating optimal resistance to Mycobacterium tuberculosis. Journal of Experimental Medicine, 202(12):1715-1724.

Batey, R. G. (1986). Aspects of pathogenesis in a mouse model of infection by Corynebacterium pseudotuberculosis. Australian Journal of Experimental Biology and Medical Science, 64(3):237249. 
Bhide, M. R., Mucha, R., Mikula, I., Kisova, L., Skrabana, R. \& Novak, M. (2009). Novel mutations in TLR genes cause hyporesponsiveness to Mycobacterium avium subsp. paratuberculosis infection. BMC Genetics, 10(1):1-11.

Brinkmann, M. M., Spooner, E., Hoebe, K., Beutler, B., Ploegh, H. L. \& Kim, Y.-M. (2007). The interaction between the ER membrane protein UNC93B and TLR3, 7, and 9 is crucial for TLR signaling. The Journal of Cell Biology, 177(2):265-275.

Brogden, K. A., Cutlip, R. C. \& Lehmkulhl, H. D. (1985). Immunogenicity of Corynebacterium pseudotuberculosis and the effect of adjuvants in mice. Journal of Comparative Pathology, 95(2):200-202.

Budhia, S., Haring, L.F., Mcconnell, I., Blacklaws B.A. (2006). Quantitation of ovine cytokine mRNA by real-time RT-PCR. Journal of Immunological Methods,309: 160-172.

Bulut, Y., Michelsen, K. S., Hayrapetian, L., Naiki, Y., Spallek, R., Singh, M. \& Arditi, M. (2005). Mycobacterium tuberculosis heat shock proteins use diverse Toll-like receptor pathways to activate pro-inflammatory signals. Journal of Biological Chemistry, 280(22):20961-20967.

Carvalho, N. B., Oliveira, F. S., Durães, F. V., Almeida, L. A., Flórido, M., Prata, L. O., . . Oliveira, S. C. (2011). Toll-like receptor 9 is required for full host resistance to Mycobacterium avium infection but plays no role in induction of Th1 responses. Infection and Immunity, 79(4):1638-1646.

Chang, J.S., Russell, G. C., Jann, O., Glass, E. J., Werling, D. \& Haig, D. M. (2009). Molecular cloning and characterization of Toll-like receptors 1-10 in sheep. Veterinary Immunology and Immunopathology, 127: 94-105.

Ferwerda, G., Kullberg, B. J., De Jong, D. J., Girardin, S. E., Langenberg, D. M. L., Van Crevel, R., . . . Netea, M. G. (2007). Mycobacterium paratuberculosis is recognized by Toll-like receptors and NOD2. Journal of Leukocyte Biology, 82(4):1011-1018.

Fontaine, M. C. \& Baird, G. J. (2008). Caseous lymphadenitis. Small Ruminant Research, 76(1-2):42-48.

Fontaine, M. C., G., B., Connor, K. M., Rudge, K., Sales, J. \& Donachie, W. (2006). Vaccination confers significant protection of sheep against infection with a virulent United Kingdom strain of Corynebacterium pseudotuberculosis. Vaccine, 245986-5996.

Guimarães, A. S., Carmo, F. B., Pauletti, R. B., Seyffert, N., Ribeiro, D., Lage, A. P., . . Gouveia, A. M. G. (2011). Caseous lymphadenitis: epidemiology, diagnosis, and control. The IIOAB Journal, 2(11):33-43.

Hajishengallis, G. \& Lambris, J. D. (2011). Microbial manipulation of receptor crosstalk in innate immunity. Nature Reviews Immunology, 1187-200.

Ito, T., Schaller, M., Hogaboam, C. M., Standiford, T. J., Chensue, S. W. \& Kunkel, S. L. (2007). TLR9 activation is a key event for the maintenance of a mycobacterial antigen-elicited pulmonary granulomatous response. European Journal of Immunology, 37(10):2847-2855.

Jo, E.-K. (2008). Mycobacterial interaction with innate receptors: TLRs, C-type lectins, and NLRs. Current Opinion in Infectious Diseases, 21(3):279-286.

Juffermans, N. P., Florquin, S., Camoglio, L., Verbon, A., Kolk, A. H., Speelman, P., . . Van der Poll, T. (2000). Interleukin-1 signaling is essential for host defense during murine pulmonary tuberculosis. The Journal of Infectious Diseases, 182(3):902-908.

Kaneko, H., Yamada, H., Mizuno, S., Udagawa, T., Kazumi, Y., Sekikawa, K. \& Sugawara, I. (1999). Role of tumor necrosis factor-alpha in Mycobacterium-induced granuloma formation in tumor necrosis factor-alpha-deficient mice. Laboratory Investigation, 79(4):379-386.

Kleinnijenhuis, J., Oosting, M., Joosten, L. A. B., Netea, M. G. \& Van Crevel, R. (2011). Innate immune recognition of Mycobacterium tuberculosis. Clinical and Developmental Immunology, 20111-13.

Lan, D. T. B., Taniguchi, S., Makino, S. i., Shirahata, T. \& Nakane, A. (1998). Role of endogenous tumor necrosis factor alpha and gamma interferon in resistance to Corynebacterium pseudotuberculosis infection in mice. Microbiology and Immunology, 42(12):863-870.

Levitz, S. M. \& Golenbock, D. T. (2012). Beyond empiricism: informing vaccine development through innate immunity research. Cell, 148(6):1284-1292. 
Mayer-Barber, K. D., Barber, D. L., Shenderov, K., White, S. D., Wilson, M. S., Cheever, A., , . Núñez, G. (2010). Cutting edge: caspase-1 independent IL-1 $\beta$ production is critical for host resistance to Mycobacterium tuberculosis and does not require TLR signaling in vivo. The Journal of Immunology, 184(7):3326-3330.

Mootoo, A., Stylianou, E., Arias, M. A. \& Reljic, R. (2009). TNF- $\alpha$ in tuberculosis: A cytokine with a split personality. Inflammation \& Allergy-Drug Targets, 8(1):53-62.

Moura-Costa, L. F. (2002). Corynebacterium pseudotuberculosis, o agente etiológico da linfadenite caseosa em caprinos. Revista de Ciências Médicas e Biológicas, 1(1):105-115.

Moura-Costa, L. F., Bahia, R. C., Carminati, R., Vale, V. L. C., Paule, B. J. A., Portela, R. W., . . Barreto, L. M. S. (2008). Evaluation of the humoral and cellular immune response to different antigens of Corynebacterium pseudotuberculosis in Canindé goats and their potential protection against caseous lymphadenitis. Veterinary Immunology and Immunopathology, 126(1-2):131-141.

Pandey, R. K., Sodhi, A., Biswas, S. K., Dahiya, Y. \& Dhillon, M. K. (2012). Mycobacterium indicus pranii mediates macrophage activation through TLR2 and NOD2 in a MyD88 dependent manner. Vaccine, 30(39):5748-5754.

Pépin, M., Seow, H. F., Corner, L., Rothel, J. S., Hodgson, A. L. M. \& Wood, P. R. (1997). Cytokine gene expression in sheep following experimental infection with various strains of Corynebacterium pseudotuberculosis differing in virulence. Veterinary Research, 28(149-163).

Plain, K. M., Purdie, A. C., Begg, D. J., Silva, K. \& Whittington, R. J. (2010). Toll-like receptor (TLR) 6 and TLR1 differentiation in gene expression studies of Johne's disease. Veterinary Immunology and Immunopathology, 137(1-2):142-148.

Pompei, L., Jang, S., Zamlynny, B., Ravikumar, S., McBride, A., Hickman, S. P. \& Salgame, P. (2007). Disparity in IL-12 release in dendritic cells and macrophages in response to Mycobacterium tuberculosis is due to use of distinct TLRs. The Journal of Immunology, 178(8):5192-5199.

Simmons, D. P., Canaday, D. H., Liu, Y., Li, Q., Huang, A., Boom, W. H. \& Harding, C. V. (2010). Mycobacterium tuberculosis and TLR2 agonists inhibit induction of type I IFN and class I MHC antigen cross processing by TLR9. The Journal of Immunology, 185(4):2405-2415.

Stefańska, I., Gieryńska, M., M., R. \& Binek, M. (2010). Survival of Corynebacterium pseudotuberculosis within macrophages and induction of phagocytes death. Polish Journal of Veterinary Sciences, 13143-149.

Stuart, M., Levitz, D. \& Golenbock, T. (2012). Beyond empiricism: Informing vaccine development through innate Immunity. Cell, 148(6):1284-1292.

Tapping, R. I. \& Tobias, P. S. (2003). Mycobacterial lipoarabinomannan mediates physical interactions between TLR1 and TLR2 to induce signaling. Journal of Endotoxin Research, 9(4):264-268.

Thirunavukkarasu, S., Silva, K., Whittington, R. J. \& Plain, K. M. (2013). In vivo and in vitro expression pattern of Toll-like receptors in Mycobacterium avium subspecies paratuberculosis infection. Veterinary Immunology and Immunopathology, 156(1-2):20-31.

Underhill, D. M., Ozinsky, A., Smith, K. D. \& Aderem, A. (1999). Toll-like receptor-2 mediates mycobacteria-induced proinflammatory signaling in macrophages. Proceedings of the National Academy of Sciences, 96(25):14459-14463.

Wang H., Zhao, J., Huang, Y., Yan, X., Meyer, A.M., Vonnahme, M. Du, K. A., Reynolds, L. P., Caton, J. S. \& Zhu, M. J.(2012). Wang, (2006). Effects of maternal plane of nutrition and increased dietary selenium in first-parity ewes on inflammatory response in the ovine neonatal gut. Journal of Animal Science, 90: 325-333.

Zang, R., Bai, J., Xu, H., Zhang, L., Yang, J., Yang, L., Lu, J. \& Wu, J. (2011). Selection of suitable reference genes for real time quantitative PCR studies in Lanzhou fat tailed sheep (ovis aries). Asian Journal of Animal and Veterinary Advances, 6(8): 789-804.

Recebido: 2 de setembro, 2019.

Aprovado: 1 de novembro, 2019

Publicado: 4 de dezembro, 2019.

Licenciamento: Este artigo é publicado na modalidade Acesso Aberto sob a licença Creative Commons Atribuição 4.0 (CC-BY 4.0), a qual permite uso irrestrito, distribuição, reprodução em qualquer meio, desde que o autor e a fonte sejam devidamente creditados. 